\title{
Do Memory B Cells Form Secondary Germinal Centers?
}

\section{Impact of Antibody Class and Quality of Memory T-Cell Help at Recall}

\author{
Louise J. McHeyzer-Williams, Chad Dufaud, and Michael G. McHeyzer-Williams
}

The Scripps Research Institute, La Jolla, California 92037

Correspondence: mcheyzer@scripps.edu

\begin{abstract}
Antigen recall can clearly induce a germinal center (GC) reaction. What has become an issue for debate are the origins of the antigen-specific B cells that form memory-response GCs (mGCs). Using antigen labeling and adoptive transfer, memory B cells expressing different antibody class can give rise to mGCs with differing efficiency. Here, we will argue that the range of class-specific memory responses reported across multiple systems represents the spectrum of memory B-cell fate and function. While the formulation of recall immunogen and location of mGCs have an important role, we propose that effective cognate regulation is the key variable influencing recall outcome. These issues remain central to contemporary efforts of rational vaccine design.
\end{abstract}

\section{GREAT DEBATES}

What are the most interesting topics likely to come up over dinner or drinks with your colleagues? Or, more importantly, what are the topics that don't come up because they are a little too controversial? In Immune Memory and Vaccines: Great Debates, Editors Rafi Ahmed and Shane Crotty have put together a collection of articles on such questions, written by thought leaders in these fields, with the freedom to talk about the issues as they see fit. This short, innovative format aims to bring a fresh perspective by encouraging authors to be opinionated, focus on what is most interesting and current, and avoid restating introductory material covered in many other reviews.

The Editors posed 13 interesting questions critical for our understanding of vaccines and immune memory to a broad group of experts in the field. In each case, several different perspectives are provided. Note that while each author knew that there were additional scientists addressing the same question, they did not know who these authors were, which ensured the independence of the opinions and perspectives expressed in each article. Our hope is that readers enjoy these articles and that they trigger many more conversations on these important topics.

Editors: Shane Crotty and Rafi Ahmed

Additional Perspectives on Immune Memory and Vaccines: Great Debates available at www.cshperspectives.org

Copyright (C) 2018 Cold Spring Harbor Laboratory Press; all rights reserved; doi: 10.1101/cshperspect.a028878 Cite this article as Cold Spring Harb Perspect Biol 2018;10:a028878 
$\mathrm{E}_{\mathrm{n}}^{\mathrm{fi}}$ ffective vaccination primes target-specific neutralizing antibodies. Challenge with the same target antigens then progressively boosts serological reactivity with varied efficacy (Corti and Lanzavecchia 2013). The cellular evolution and molecular mechanisms that drive antibody-based protection are being scrutinized with heightened resolution in new experimental models (McHeyzer-Williams et al. 2012; Victora and Nussenzweig 2012). Subspecialized follicular helper $\mathrm{T}\left(\mathrm{T}_{\mathrm{FH}}\right)$ cells are now recognized as central cognate regulators of primary B-cell immunity with less understood of their role in recall (Crotty 2011; Qi 2016; Vinuesa et al. 2016). It remains of utmost importance to unravel and target all facets of recall regulation to optimize vaccine-driven immune protection.

In this perspective, we focus on the response to antigen recall. We discuss the results from multiple groups across various experimental models that seek to address the origins of B cells that rediversify B-cell antigen receptors (BCRs) on recall. Components of the memory-response germinal center ( $\mathrm{mGC}$ ) reaction will receive special emphasis with discussion of current thinking in cognate $\mathrm{T}_{\mathrm{FH}}$ function and its role in recall. In reviewing this recent literature, we seek to identify the cellular targets and recall conditions that optimize antibody-based immune protection.

\section{ANTIGEN-SPECIFIC B-CELL MEMORY}

Early studies with hybridoma and BCR sequencing clearly showed the progressive increase in antigen-specific BCR diversification with prime-boost regime (Allen et al. 1987; Berek and Milstein 1987). Direct molecular analyses (Berek et al. 1991; Jacob et al. 1991b) supported the long-held notion that the primary-response GC ( $\mathrm{pGC}$ ) reaction promoted ongoing BCR diversification (MacLennan 1994). While antigen-specific GCs emerged in primary reactive lymphoid sites (McHeyzer-Williams et al. 1993), these pGCs resolved after only a few weeks (Jacob et al. 1991a; Weisel et al. 2016). Furthermore, early adoptive transfer studies of high-affinity memory B cells produced expansion and plasma-cell (PC) differentiation without BCR rediversification (Siekevitz et al. 1987).
Hence, selective recruitment with preferential clonal expansion could account for ongoing antibody affinity maturation without BCR rediversification at recall.

Antigen-binding (Hayakawa et al. 1987) and single-cell assessment of BCR sequence (McHeyzer-Williams et al. 1991, 1993) provided direct access to antigen-specific B-cell memory. Only a few of these earlier studies focused on the antigen-specific recall response (Hayakawa et al. 1987; McHeyzer-Williams et al. 1991, 2000; Shapiro-Shelef et al. 2003). Direct evidence for emergent $\mathrm{B} 220^{+} \mathrm{CD} 138^{-} \mathrm{GL}^{+}$antigen-binding secondary GC formation at recall in situ was most clearly observed in the absence of Blimp-1 expression (Shapiro-Shelef et al. 2003). In this context, PC differentiation was absent and the GC pathway exaggerated both in the primary and recall responses (ShapiroShelef et al. 2003). Hence, it appeared that secondary GC reactions could appear at recall but the origins of the antigen-specific B cells involved remain untested.

Direct sequencing of circulating antigenspecific PCs after influenza vaccine boost provided the next line of evidence for memory BCR (mBCR) rediversification (Wrammert et al 2008). In these human cohorts, there were multiple antigen-specific PC expansions with evidence of intraclonal BCR diversity (Wrammert et al. 2008). While highly suggestive of secondary GC formation, these studies focused on the outcome of recall responses in the blood and could not resolve their presence at recall.

\section{MEMORY GC REACTION}

At this point, a variety of murine immunization/vaccination models were used to assess memory B-cell fate at recall. Noelle and colleagues (Benson et al. 2009) used phycoerythrin (PE) in alum primarily to test the earlier notion of bystander memory reactivation (Bernasconi et al. 2002). In the process, they observed no local secondary GC formation at recall with soluble antigen or in the presence of CpG adjuvant (Benson et al. 2009). Kurosaki's group (Aiba et al. 2010) focused on hapten-protein $(\mathrm{NP}-\mathrm{KLH})$ in alum using soluble recall to 
show the requirement of CD4 T cells and antigen presentation by $\mathrm{IgG1}^{+}$memory $\mathrm{B}$ cells for reactivation and antibody production. In subsequent studies (Kometani et al. 2013), this group also shows the Bach-2-dependent skewing of $\mathrm{IgG}^{+}$memory B cells into memoryresponse $\mathrm{PC}(\mathrm{mPC})$ differentiation at recall.

Weill, Reynaud, and colleagues (Dogan et al. 2009) used in vivo temporal fate mapping to study B-cell memory. In this model, activation-induced cytidine deaminase (AID)-expressing cells were indelibly labeled (enhanced yellow fluorescent protein [EYFP]) after priming and recall responses. SRBC immunization (classic particulate antigen) induced robust antibody and long-lasting pGC responses while adoptive transfer revealed memory Bcell function. In this model, $\operatorname{IgM}^{+}$memory B cells produced mGCs and mPCs, while $\mathrm{IgG}^{+}$ memory $\mathrm{B}$ cells only gave rise to mPCs. In this model, antibody class exerted a strong differential impact on memory B-cell fate and function.

Jenkins and colleagues (Pape et al. 2011) focused on the longevity of class-switched and $\mathrm{IgM}^{+}$memory using the PE-response and complete Freunds adjuvant (CFA). PE-specific $\mathrm{IgM}^{+}$memory survived at constant levels for extended periods while switched-memory decayed at a considerable rate. Nevertheless, switched-memory dominated the recall response while present but $\operatorname{IgM}^{+}$memory supported more robust $\mathrm{mGC}$ responses on adoptive transfer. In contrast, Bachmann's group (Zabel et al. 2014) reported robust $\mathrm{mPC}$ formation following virus-like-particle (VLP) prime and boost after adoptive transfer with little mGC formation from either $\operatorname{IgM}^{+}$or $\mathrm{IgG}^{+}$memory B cells.

Pepper and colleagues (Krishnamurty et al. 2016) tracked antigen-specific B-cell memory in a murine malaria infection. These studies revealed antigen-binding $\operatorname{IgD}^{+}, \operatorname{IgM}^{+}$, and swiched memory compartments after infection and reinfection. Even in the presence of greater numbers of switched memory, at recall, $\operatorname{IgM}^{+}$ memory cells dominated expansion and robust $\mathrm{mPC}$ responses. Hence, $\mathrm{mGCs}$ are not obligatory components of all recall response conditions and the formulation of immunization and/or the recall response will differentially impact memory-response fate at reactivation.

In more recent studies, Nussenzweig's group (Gitlin et al. 2016) dissected the impact of classswitch versus hypermutation on switched-memory B-cell fate. In a complex genetic model, IgG1 class-switch was driven by Cre-recombinase and dissociated from AID-dependent BCR diversification. Under these conditions, antigen-driven $\mathrm{IgG1}^{+} \mathrm{PC}$ differentiation was exaggerated but had no demonstrable impact on pGC expansion. Conversely, BCR hypermutation compromised $\mathrm{IgGl}^{+}$memory longevity with evidence for increased self-reactive mBCRs after pGC experience. These findings suggest that BCR diversification more than class-switch may impact memory B-cell longevity. Persistence of memory B cells after initial priming then becomes a significant component in the capacity to respond at recall. The role for memory $\mathrm{T}_{\mathrm{FH}}$ $\left(\mathrm{mT}_{\mathrm{FH}}\right)$ cells remains unclear and a potentially confounding variable in many of these studies.

Takemori and colleagues (Kaji et al. 2013) more directly addressed the question of mBCR rediversification using adoptive transfer and clonal sequence reconstruction. In this NPCGG model driven by alum, both mutated and unmutated memory B cells could rediversify BCRs at transfer and recall in ways that were AID-dependent (Kaji et al. 2013). Similar studies from Shlomchik's group (Zuccarino-Catania et al. 2014) indicate that the phenotypic subdivision of B-cell memory, based on CD80 and PD-L2 regardless of antibody class, predicts differential memory-response outcome. Memory cells double positive for these markers skewed toward mPC formation, whereas the double-negative fraction produced robust mGC reactions. These latter studies indicate intrinsic memory B-cell attributes or subset-specific extrinsic reactivation difference that may further impact memory B-cell fate.

\section{mGC B-CELL PROGRAMS AT THE SINGLE-CELL LEVEL}

We too have directly addressed the question of class-switched memory B-cell fate (Wang et al. 2012; McHeyzer-Williams et al. 2015). In the 
first study, we identified a unique role for the transcription factor T-bet in the survival and reactivation of IgG2 $\mathrm{a}^{+}$memory B cells at recall (Wang et al. 2012). Interestingly, T-bet was also expressed in $\mathrm{IgG1}^{+}$memory B cells but did not exert the same essential function. We believe these studies indicate that class-switch goes beyond the recombination event to initiate separable and divergent molecular programs within class-specific memory B-cell compartments.

In the second study, we used adoptive transfer across multiple models to show that classswitched memory B cells could drive mGCs in the adoptive host (McHeyzer-Williams et al. 2015). Hapten-carrier (NP-KLH) priming with TLR4 agonist (monophosphoryl lipid A [MPL]) generate dominantly IgG2a/2b switched-memory compartments that could form mGC reactions in either nonspecific BCR transgenic or wild-type hosts. In this models, $\operatorname{IgM}^{+}$memory B cells predominantly formed mPCs. We had previously shown that local antigen-specific $\mathrm{T}_{\mathrm{H}}$ cell responses were substantially more robust and had higher affinity with MPL than CFA or alum, suggesting a secondary role for cognate regulation (Malherbe et al. 2008). Further, we suspect that emphasis on lymph node (LN) priming rather than the spleen induced a quantitatively and qualitatively distinct memory landscape (Fazilleau et al. 2007, 2009a,b).

In these studies, we were also able to connect the cellular phenotype, gene expression and BCR repertoire of individual responding antigen-specific mGC B cells (McHeyzer-Williams et al. 2015). Taken together, we could divide single mGC B cells into four separable stages of the mGC cycle based initially on Cd83 and Polh gene expression. Once "gated" on major cellular divisions for these two mRNA species, expression assorted differentially across a range of putative GC functions (depicted in Fig. 1). Importantly, there was a balance of mGC B cells across all four subsets over time and these divisions could be found within the progeny of individual clones. Hence, we could track the dynamics of $\mathrm{mGC}$ reactions within the clonal progeny of class-switched memory B cells.

These mGC B-cell subsets were also found in the pGC compartment and the proposed stages consistent with earlier dynamic imaging studies (Victora and Nussenzweig 2012). The iterative pGC cycles of selection followed by $\mathrm{BCR}$ diversification drive rapid clonal evolution under the cognate guidance of GC-localized $\mathrm{T}_{\mathrm{FH}}$ cells (Crotty 2011; McHeyzer-Williams et al. 2012; Victora and Nussenzweig 2012; Vinuesa et al. 2016). Dynamic imaging provided evidence of B-cell antigen scanning on follicular dendritic cells (FDCs), cognate contact with GC- $\mathrm{T}_{\mathrm{FH}}$ cells, light-dark zone recycling, and robust local proliferation (Allen et al. 2007; Schwickert et al. 2007). Elegant photolabeling studies tracked zonal movement in real time (Victora et al. 2010), enabling many of the central attributes of the pGC to be measured directly for the first time (Victora and Nussenzweig 2012). Finally, the elegant use of the "confetti" mice with temporally controlled clonal labeling capacity (Tas et al. 2016) provided a new means to access BCR diversification in real time. Hence, we propose essentially similar functions for the mGC cycle, but suggest that distinct precursors are produced at priming and differentially reactivated at recall.

\section{FOLLICULAR HELPER T CELLS}

Extending to GC- $\mathrm{T}_{\mathrm{FH}}$ studies, the clonal dynamics and regional movements of GC- $\mathrm{T}_{\mathrm{FH}}$ cells (Shulman et al. 2013), their costimulatory effect, and impact on clonal selection have also been dynamically tracked (Shulman et al. 2014; Liu et al. 2015; Qi 2016). Although the events associated with the mGC cycle are reminiscent of pGC workings, the intrinsic programs and regulatory requirements of switched-memory B cells may vary substantially at recall.

Antibody class may also impact pGC persistence and/or memory B-cell production after initial priming. There have been earlier reports of distinct $\mathrm{T}_{\mathrm{FH}}$ cell subsets associated with pGC B cells of a different class (Reinhardt et al. 2009). Combinations of TLR agonists with nanoparticle delivery of antigen promoted efficient classswitch and extended local LN response (Kasturi et al. 2011). Expressing the intracellular IgG tail on naïve $B$ cells promoted excessive clonal bursts (Martin and Goodnow 2002). Similar 
Do Memory B Cells Form Secondary Germinal Centers?
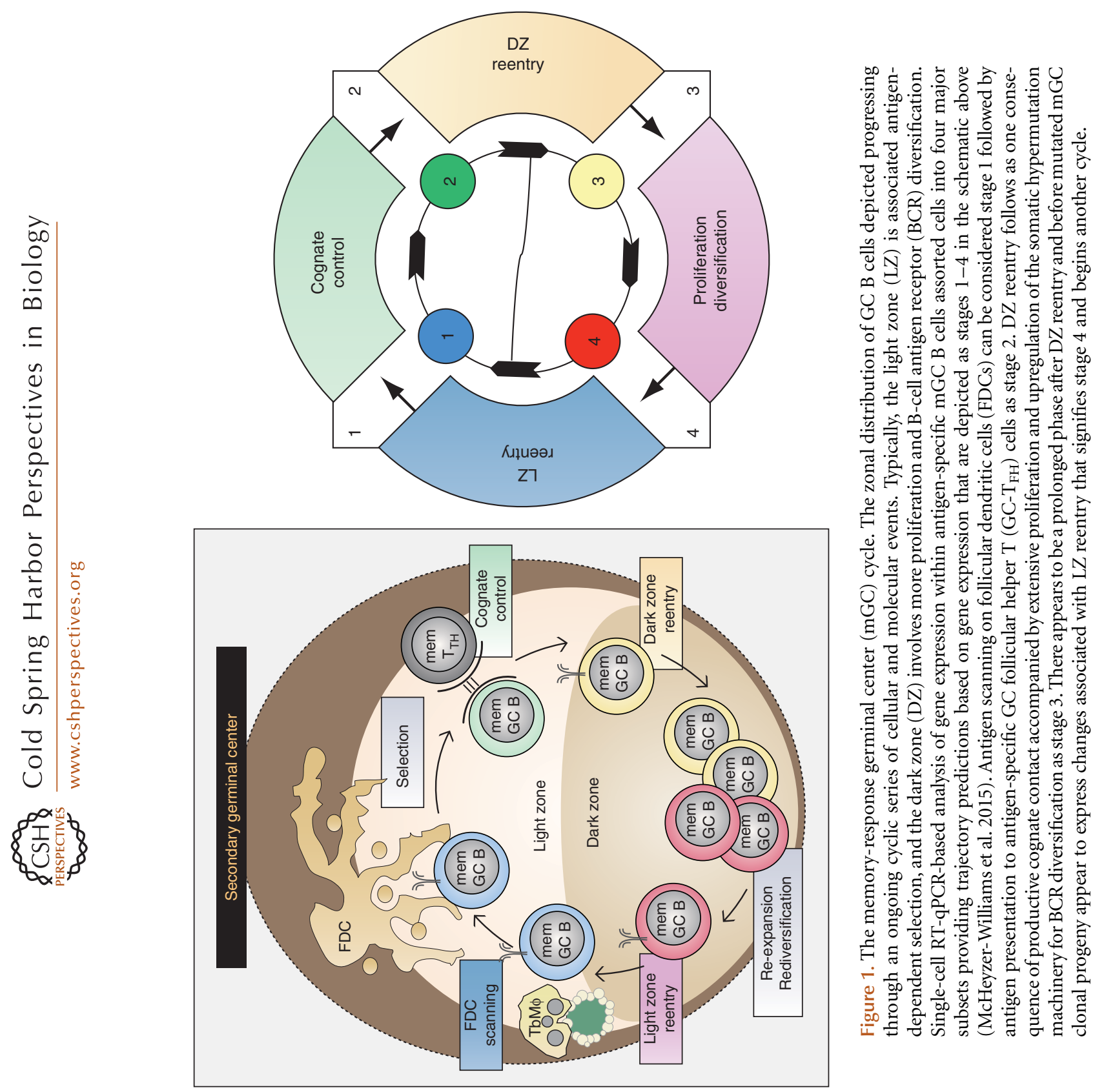


\section{L.J. McHeyzer-Williams et al.}

findings indicate intrinsic differences in signaling for IgG switched B cells (Wakabayashi et al. 2002; Horikawa et al. 2007; Waisman et al. 2007). There is also evidence for alterations in biophysical properties of IgG1 BCRs (Liu et al. 2010). It is difficult to predict how these changes may impact pGC selection. Hence, the quality of the initial priming event substantially impacts the recall response spectrum permitting a range of outcomes imprinted at the outset.

Selection of preferred responding clones amplifies effective BCR specificities (Schwickert et al. 2011) with some impact on the bifurcation of early differentiation (Schwickert et al. 2007, 2009). Under the cognate guidance $T_{F H}$ cells, some antigen-specific $B$ cells undergo class- switch recombination (CSR) and PC differentiation, whereas others rapidly expand and organize to form the pGC reaction (Qi et al. 2008). Recent studies suggest the GC- $\mathrm{T}_{\mathrm{FH}}$ cells undergo further changes that progressively impact pGC B-cell selection (Weinstein et al. 2016). These earliest events may have long-term consequences in shaping the memory potential at recall through establishment of the appropriate $\mathrm{mT}_{\mathrm{FH}}$ compartments.

In Figure 2, we depict the spectrum of outcomes plausible for the recall response to a $\mathrm{T}_{\mathrm{H}^{-}}$ cell-dependent memory response. Accordingly, cognate T-cell help is depicted as an obligatory initial event and memory B cells of different antibody class are not separated. We propose

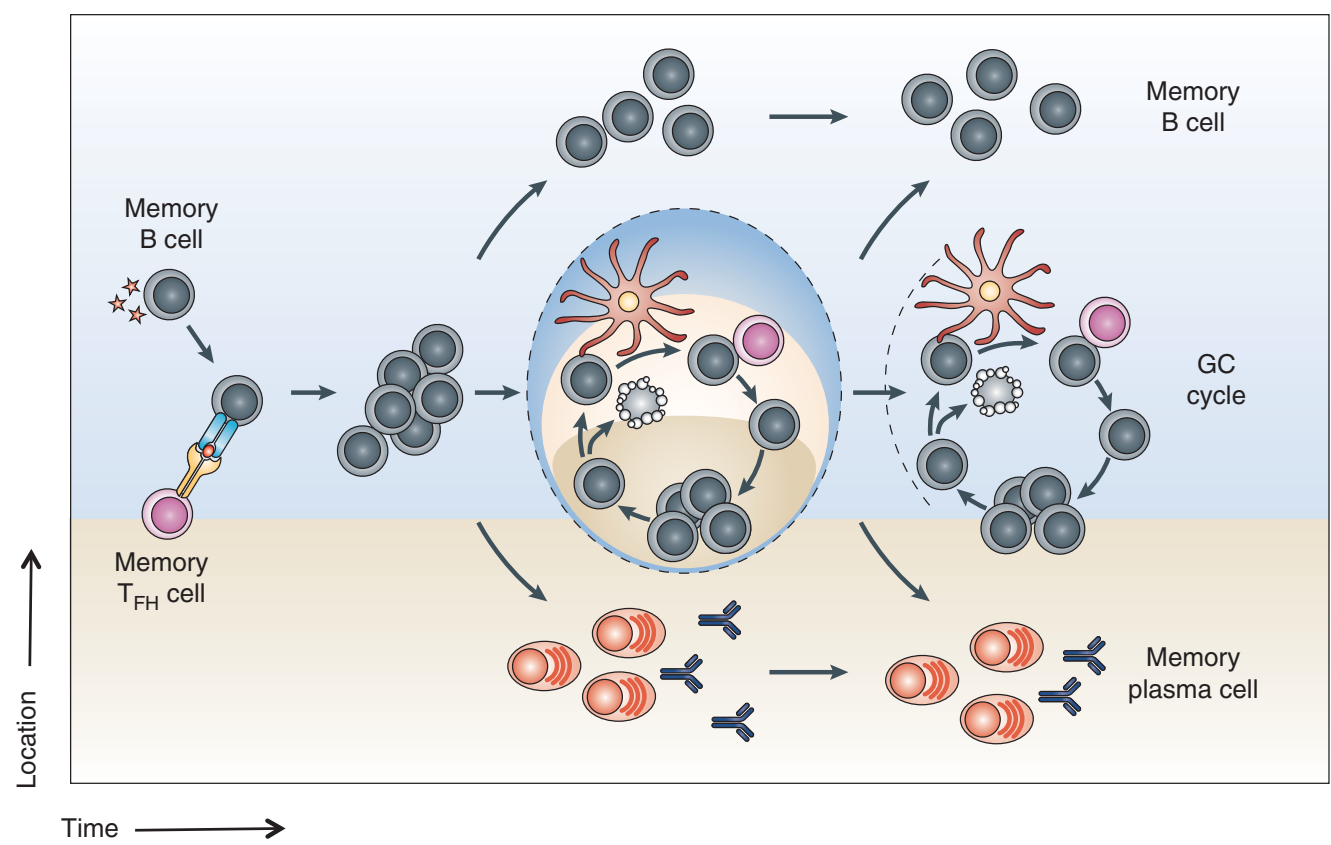

Figure 2. Reprogramming B-cell memory. In this model, we depict the predicted potential associated with a memory follicular helper $\mathrm{T}\left(\mathrm{T}_{\mathrm{FH}}\right)$-driven memory $\mathrm{B}$-cell response to recall. Here, we suggest that the memory $\mathrm{B}$ cell is the dominant presenter of recall antigen and that its earliest requirement for ongoing reactivity is cognate contact with antigen-specific memory $\mathrm{T}_{\mathrm{FH}}$ cells. In this scenario, we propose that both IgM and class-switched memory can be precursors of this recall response. Major outcomes depicted then include initial activation and expansion of responding clones and bifurcation into differentiation pathways of memory B-cell replenishment and memory-response plasma-cell ( $\mathrm{mPC}$ ) formation that do not require B-cell antigen receptor (BCR) rediversification. These outcomes expand/replenish the precursor pool and provide immediate effector function. The third outcome is the de novo formation of the memory-response germinal center (mGC) reaction, which can then give rise to further affinity maturation with higher-affinity memory B cells and mPCs for long-lived, further-matured compartments of memory. 
Do Memory B Cells Form Secondary Germinal Centers?

that recall outcomes can be considered across the full spatiotemporal spectrum as depicted. Initial memory responders can expand to selfreplenish and differentiate into mPCs as early robust outcomes. mGC formation provides a secondary niche to drive BCR rediversification with cognate $\mathrm{GC}-\mathrm{mT}_{\mathrm{FH}}$ cells as the central presumptive regulator. These mGCs would produce higher-affinity post-mGC memory B cells and $\mathrm{mPC}$ than their earlier counterparts.

\section{THE CONTEMPORARY VACCINE EFFORT}

The tracking of memory B-cell responses in humans has undergone explosive activity in recent years. Antigen-labeling and judicious timing after antigen exposure coupled to deep sequencing enables dissection of antigen-specific BCR repertoires to complex antigens in humans. The range of studies in this arena is expansive and will not be reviewed here. However, it is pertinent to highlight the recent direction of research into HIV vaccines in which viral escape is driven by effective neutralizing antibody responses. Landmark studies by the Haynes group (Liao et al. 2013; Gao et al. 2014) outlined the coevolution between host immunity and viral escape that eventually produced broad neutralization. These studies highlighted the need to understand and direct ongoing clonal evolution with prime-boost vaccines.

In HIV infection, the problem seemed even more complicated such that the germline precursors of broadly neutralizing antibodies had negligible binding to the original neutralizing epitope. Now through antigen redesign (Jardine et al. 2016) and sequential immunization (Briney et al. 2016; Escolano et al. 2016; Sok et al. 2016; Tian et al. 2016), germline precursors can be targeted in humanized mouse models to drive broadly neutralizing outcomes after effective affinity maturation. This most recent example highlights the immediate and current need to understand the rules that govern clonal evolution within the GC reaction. Antigen design will permit initiation of appropriate memory B-cell and $\mathrm{mT}_{\mathrm{FH}}$ compartments. Targeted recall responses that promote and permit BCR rediversification to redirect $\mathrm{BCR}$ binding to a related but altered vaccine target promotes the appropriate evolution of broadly neutralizing reactivity within a series of $\mathrm{mGC}$ reactions.

\section{CONCLUSIONS}

Overall, we argue that there is ample evidence that antigen recall promotes a secondary GC reaction. Initial and subsequent studies of human peripheral blood and local analyses of model immune responses indicates that already matured mBCRs can rediversify through involvement in secondary GC reactions. Across multiple models, the capacity of $\operatorname{IgM}^{+}$and class-switched memory B cells varies depending on the form of antigen, adjuvant used and location of the priming event. It is also likely that the quality and quantity of cognate $\mathrm{mT}_{\mathrm{FH}}$ compartments influence these outcomes in ways that remain central but unresolved.

Finally, we propose that the intention of the recall determines the strategy to be used. In the first scenario, priming with expectation of viral escape, flexibility in the recall response may be what is required. Hence, the less-mutated and potentially broadly focused IgM mBCR repertoire may be beneficial to target for the recall. Alternatively, if the highest affinity to the same target antigen is needed for long-term highaffinity neutralizing protection, then affinitymatured class-switched memory B cells may be the best target for the recall. In both scenarios, the requisite cognate $\mathrm{mT}_{\mathrm{FH}}$ compartment will be needed to induce the $\mathrm{mGC}$ reaction. To this end, it remains critical to unravel the rules of cellular engagement and molecular mechanisms driving $\operatorname{IgM}^{+}$and class-switched memory $\mathrm{B}$-cell clonal evolution in the $\mathrm{mGC}$ reaction at recall.

\section{REFERENCES}

Aiba Y, Kometani K, Hamadate M, Moriyama S, Sakaue-
Sawano A, Tomura M, Luche H, Fehling HJ, Casellas R,
Kanagawa O, et al. 2010. Preferential localization of IgG
memory B cells adjacent to contracted germinal centers.
Proc Natl Acad Sci 107: 12192-12197.
Allen D, Cumano A, Dildrop R, Kocks C, Rajewsky K, Ra-
jewsky N, Roes J, Sablitzky F, Siekevitz M. 1987. Timing,
genetic requirements and functional consequences of 
L.J. McHeyzer-Williams et al.

somatic hypermutation during B-cell development Immunol Rev 96: 5-22.

Allen CD, Okada T, Tang HL, Cyster JG. 2007. Imaging of germinal center selection events during affinity maturation. Science 315: 528-531.

Benson MJ, Elgueta R, Schpero W, Molloy M, Zhang W, Usherwood E, Noelle RJ. 2009. Distinction of the memory $\mathrm{B}$ cell response to cognate antigen versus bystander inflammatory signals. J Exp Med 206: 2013-2025.

Berek C, Milstein C. 1987. Mutation drift and repertoire shift in the maturation of the immune response. Immunol Rev 96: 23-41.

Berek C, Berger A, Apel M. 1991. Maturation of the immune response in germinal centers. Cell 67: 1121-1129.

Bernasconi NL, Traggiai E, Lanzavecchia A. 2002. Maintenance of serological memory by polyclonal activation of human memory B cells. Science 298: 2199-2202.

Briney B, Sok D, Jardine JG, Kulp DW, Skog P, Menis S, Jacak R, Kalyuzhniy O, de Val N, Sesterhenn F, et al. 2016 Tailored immunogens direct affinity maturation toward HIV neutralizing antibodies. Cell 166: 1459-1470, e1411.

Corti D, Lanzavecchia A. 2013. Broadly neutralizing antiviral antibodies. Annu Rev Immunol 31: 705-742.

Crotty S. 2011. Follicular helper CD4 T cells $\left(\mathrm{T}_{\mathrm{FH}}\right)$. Annu Rev Immunol 29: 621-663.

Dogan I, Bertocci B, Vilmont V, Delbos F, Megret J, Storck S, Reynaud CA, Weill JC. 2009. Multiple layers of B cell memory with different effector functions. Nat Immunol 10: $1292-1299$.

Escolano A, Steichen JM, Dosenovic P, Kulp DW, Golijanin J, Sok D, Freund NT, Gitlin AD, Oliveira T, Araki T, et al 2016. Sequential immunization elicits broadly neutralizing anti-HIV-1 antibodies in Ig knockin mice. Cell 166: 1445-1458.e12.

Fazilleau N, Eisenbraun MD, Malherbe L, Ebright JN, Pogue-Caley RR, McHeyzer-Williams LJ, McHeyzerWilliams MG. 2007. Lymphoid reservoirs of antigen-specific memory T helper cells. Nat Immunol 8: 753-761.

Fazilleau N, Mark L, McHeyzer-Williams LJ, McHeyzerWilliams MG. 2009a. Follicular helper T cells: Lineage and location. Immunity 30: 324-335.

Fazilleau N, McHeyzer-Williams LJ, Rosen H, McHeyzerWilliams MG. 2009b. The function of follicular helper $\mathrm{T}$ cells is regulated by the strength of $\mathrm{T}$ cell antigen receptor binding. Nat Immunol 10: 375-384.

Gao F, Bonsignori M, Liao HX, Kumar A, Xia SM, Lu X, Cai F, Hwang KK, Song H, Zhou T, et al. 2014. Cooperation of $\mathrm{B}$ cell lineages in induction of HIV-1-broadly neutralizing antibodies. Cell 158: 481-491.

Gitlin AD, von Boehmer L, Gazumyan A, Shulman Z, Oliveira TY, Nussenzweig MC. 2016. Independent roles of switching and hypermutation in the development and persistence of B lymphocyte memory. Immunity 44: 769-781.

Hayakawa K, Ishii R, Yamasaki K, Kishimoto T, Hardy RR. 1987. Isolation of high-affinity memory B cells: Phycoerythrin as a probe for antigen-binding cells. Proc Natl Acad Sci 84: 1379-1383.

Horikawa K, Martin SW, Pogue SL, Silver K, Peng K, Takatsu K, Goodnow CC. 2007. Enhancement and suppression of signaling by the conserved tail of IgG memory-type B cell antigen receptors. J Exp Med 204: 759-769.

Jacob J, Kassir R, Kelsoe G. 1991a. In situ studies of the primary immune response to (4-hydroxy-3-nitrophenyl) acetyl. I: The architecture and dynamics of responding cell populations. J Exp Med 173: 1165-1175.

Jacob J, Kelsoe G, Rajewsky K, Weiss U. 1991b. Intraclonal generation of antibody mutants in germinal centres. Nature 354: 389-392.

Jardine JG, Kulp DW, Havenar-Daughton C, Sarkar A, Briney B, Sok D, Sesterhenn F, Ereno-Orbea J, Kalyuzhniy O, Deresa I, et al. 2016. HIV-1 broadly neutralizing antibody precursor B cells revealed by germline-targeting immunogen. Science 351: 1458-1463.

Kaji T, Furukawa K, Ishige A, Toyokura I, Nomura M, Okada M, Takahashi Y, Shimoda M, Takemori T. 2013. Both mutated and unmutated memory B cells accumulate mutations in the course of the secondary response and develop a new antibody repertoire optimally adapted to the secondary stimulus. Int Immunol 25: 683-695.

Kasturi SP, Skountzou I, Albrecht RA, Koutsonanos D, Hua T, Nakaya HI, Ravindran R, Stewart S, Alam M, Kwissa M, et al. 2011. Programming the magnitude and persistence of antibody responses with innate immunity. Nature 470: 543-547.

Kometani K, Nakagawa R, Shinnakasu R, Kaji T, Rybouchkin A, Moriyama S, Furukawa K, Koseki H, Takemori T, Kurosaki T. 2013. Repression of the transcription factor Bach2 contributes to predisposition of IgG1 memory B cells toward plasma cell differentiation. Immunity 39: 136-147.

Krishnamurty AT, Thouvenel CD, Portugal S, Keitany GJ, Kim KS, Holder A, Crompton PD, Rawlings DJ, Pepper M. 2016. Somatically hypermutated plasmodium-specific $\mathrm{IgM}^{+}$memory B cells are rapid, plastic, early responders upon malaria rechallenge. Immunity 45: 402-414.

Liao HX, Lynch R, Zhou T, Gao F, Alam SM, Boyd SD, Fire AZ, Roskin KM, Schramm CA, Zhang Z, et al. 2013. Coevolution of a broadly neutralizing HIV-1 antibody and founder virus. Nature 496: 469-476.

Liu W, Meckel T, Tolar P, Sohn HW, Pierce SK. 2010. Intrinsic properties of immunoglobulin IgG1 isotype-switched $\mathrm{B}$ cell receptors promote microclustering and the initiation of signaling. Immunity 32: 778-789.

Liu D, Xu H, Shih C, Wan Z, Ma X, Ma W, Luo D, Qi H. 2015. T-B-cell entanglement and ICOSL-driven feedforward regulation of germinal centre reaction. Nature 517: $214-218$.

MacLennan IC. 1994. Germinal centers. Annu Rev Immunol 12: $117-139$.

Malherbe L, Mark L, Fazilleau N, McHeyzer-Williams LJ, McHeyzer-Williams MG. 2008. Vaccine adjuvants alter TCR-based selection thresholds. Immunity 28: 698-709.

Martin SW, Goodnow CC. 2002. Burst-enhancing role of the IgG membrane tail as a molecular determinant of memory. Nat Immunol 3: 182-188.

McHeyzer-Williams MG, Nossal GJ, Lalor PA. 1991. Molecular characterization of single memory B cells. Nature 350: 502-505. 
Do Memory B Cells Form Secondary Germinal Centers?

McHeyzer-Williams MG, McLean MJ, Lalor PA, Nossal GJ. 1993. Antigen-driven B cell differentiation in vivo. J Exp Med 178: 295-307.

McHeyzer-Williams LJ, Cool M, McHeyzer-Williams MG. 2000. Antigen-specific B cell memory: Expression and replenishment of a novel b220 memory B cell compartment. J Exp Med 191: 1149-1166.

McHeyzer-Williams M, Okitsu S, Wang N, McHeyzer-Williams L. 2012. Molecular programming of B cell memory. Nat Rev Immunol 12: 24-34.

McHeyzer-Williams LJ, Milpied PJ, Okitsu SL, McHeyzerWilliams MG. 2015. Class-switched memory B cells remodel BCRs within secondary germinal centers. Nat Immunol 16: 296-305.

Pape KA, Taylor JJ, Maul RW, Gearhart PJ, Jenkins MK. 2011. Different B cell populations mediate early and late memory during an endogenous immune response. Science 331: 1203-1207.

Qi H. 2016. T follicular helper cells in space-time. Nat Rev Immunol 16: 612-625.

Qi H, Cannons JL, Klauschen F, Schwartzberg PL, Germain RN. 2008. SAP-controlled T-B cell interactions underlie germinal centre formation. Nature 455: 764-769.

Reinhardt RL, Liang HE, Locksley RM. 2009. Cytokine-secreting follicular T cells shape the antibody repertoire. Nat Immunol 10: 385-393.

Schwickert TA, Lindquist RL, Shakhar G, Livshits G, Skokos D, Kosco-Vilbois MH, Dustin ML, Nussenzweig MC. 2007. In vivo imaging of germinal centres reveals a dynamic open structure. Nature 446: 83-87.

Schwickert TA, Alabyev B, Manser T, Nussenzweig MC. 2009. Germinal center reutilization by newly activated B cells. J Exp Med 206: 2907-2914.

Schwickert TA, Victora GD, Fooksman DR, Kamphorst AO, Mugnier MR, Gitlin AD, Dustin ML, Nussenzweig MC. 2011. A dynamic T-cell-limited checkpoint regulates affinity-dependent B cell entry into the germinal center. J Exp Med 208: 1243-1252.

Shapiro-Shelef M, Lin KI, McHeyzer-Williams LJ, Liao J, McHeyzer-Williams MG, Calame K. 2003. Blimp-1 is required for the formation of immunoglobulin secreting plasma cells and pre-plasma memory B cells. Immunity 19: $607-620$.

Shulman Z, Gitlin AD, Targ S, Jankovic M, Pasqual G, Nussenzweig MC, Victora GD. 2013. T follicular helper cell dynamics in germinal centers. Science 341: 673-677.

Shulman Z, Gitlin AD, Weinstein JS, Lainez B, Esplugues E, Flavell RA, Craft JE, Nussenzweig MC. 2014. Dynamic signaling by $\mathrm{T}$ follicular helper cells during germinal center B cell selection. Science 345: 1058-1062.

Siekevitz M, Kocks C, Rajewsky K, Dildrop R. 1987. Analysis of somatic mutation and class switching in naïve and memory $\mathrm{B}$ cells generating adoptive primary and secondary responses. Cell 48: 757-770.
Sok D, Briney B, Jardine JG, Kulp DW, Menis S, Pauthner M, Wood A, Lee EC, Le KM, Jones M, et al. 2016. Priming HIV-1 broadly neutralizing antibody precursors in human Ig loci transgenic mice. Science 353: 1557-1560.

Tas JM, Mesin L, Pasqual G, Targ S, Jacobsen JT, Mano YM, Chen CS, Weill JC, Reynaud CA, Browne EP, et al. 2016. Visualizing antibody affinity maturation in germinal centers. Science 351: 1048-1054.

Tian M, Cheng C, Chen X, Duan H, Cheng HL, Dao M, Sheng Z, Kimble M, Wang L, Lin S, et al. 2016. Induction of HIV neutralizing antibody lineages in mice with diverse precursor repertoires. Cell 166: 1471-1484.e18.

Victora GD, Nussenzweig MC. 2012. Germinal centers. Annu Rev Immunol 30: 429-457.

Victora GD, Schwickert TA, Fooksman DR, Kamphorst AO, Meyer-Hermann M, Dustin ML, Nussenzweig MC. 2010 Germinal center dynamics revealed by multiphoton microscopy with a photoactivatable fluorescent reporter. Cell 143: 592-605.

Vinuesa CG, Linterman MA, Yu D, MacLennan IC. 2016. Follicular helper T cells. Annu Rev Immunol 34: 335-368.

Waisman A, Kraus M, Seagal J, Ghosh S, Melamed D, Song J, Sasaki Y, Classen S, Lutz C, Brombacher F, et al. 2007. IgG1 B cell receptor signaling is inhibited by CD22 and promotes the development of $\mathrm{B}$ cells whose survival is less dependent on Ig $\alpha / \beta$. J Exp Med 204: 747-758.

Wakabayashi C, Adachi T, Wienands J, Tsubata T. 2002. A distinct signaling pathway used by the IgG-containing B cell antigen receptor. Science 298: 2392-2395.

Wang NS, McHeyzer-Williams LJ, Okitsu SL, Burris TP, Reiner SL, McHeyzer-Williams MG. 2012. Divergent transcriptional programming of class-specific B cell memory by T-bet and ROR $\alpha$. Nat Immunol 13: 604-611.

Weinstein JS, Herman EI, Lainez B, Licona-Limon P, Esplugues E, Flavell R, Craft J. 2016. $\mathrm{TF}_{\mathrm{H}}$ cells progressively differentiate to regulate the germinal center response. Nat Immunol 17: 1197-1205.

Weisel FJ, Zuccarino-Catania GV, Chikina M, Shlomchik MJ. 2016. A temporal switch in the germinal center determines differential output of memory B and plasma cells. Immunity 44: 116-130.

Wrammert J, Smith K, Miller J, Langley WA, Kokko K, Larsen C, Zheng NY, Mays I, Garman L, Helms C, et al. 2008. Rapid cloning of high-affinity human monoclonal antibodies against influenza virus. Nature 453: 667-671.

Zabel F, Mohanan D, Bessa J, Link A, Fettelschoss A, Saudan P, Kundig TM, Bachmann MF. 2014. Viral particles drive rapid differentiation of memory $B$ cells into secondary plasma cells producing increased levels of antibodies. J Immunol 192: 5499-5508.

Zuccarino-Catania GV, Sadanand S, Weisel FJ, Tomayko MM, Meng H, Kleinstein SH, Good-Jacobson KL, Shlomchik MJ. 2014. CD80 and PD-L2 define functionally distinct memory B cell subsets that are independent of antibody isotype. Nat Immunol 15: 631-637. 


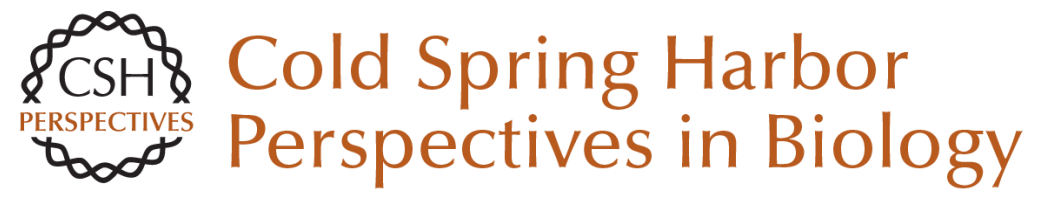

\title{
Do Memory B Cells Form Secondary Germinal Centers?: Impact of Antibody Class and Quality of Memory T-Cell Help at Recall
}

\author{
Louise J. McHeyzer-Williams, Chad Dufaud and Michael G. McHeyzer-Williams
}

Cold Spring Harb Perspect Biol 2018; doi: 10.1101/cshperspect.a028878 originally published online March 20, 2017

Subject Collection Immune Memory and Vaccines: Great Debates

Is There Natural Killer Cell Memory and Can It Be Harnessed by Vaccination?: Can Natural Killer and CD8 T Cells Switch Jobs?

Christine A. Biron and Marcus Altfeld

Is There Natural Killer Cell Memory and Can It Be Harnessed by Vaccination?: Vaccination Strategies Based on NK Cell and ILC Memory Megan A. Cooper, Todd A. Fehniger and Marco Colonna

Is It Possible to Develop Cancer Vaccines to Neoantigens, What Are the Major Challenges, and How Can These Be Overcome?: Neoantigens as Vaccine Targets for Cancer

Haydn T. Kissick

Is It Possible to Develop Cancer Vaccines to Neoantigens, What Are the Major Challenges, and How Can These Be Overcome?: Neoantigens: Nothing New in Spite of the Name

Olivera J. Finn and Hans-Georg Rammensee

Which Dengue Vaccine Approach Is the Most Promising, and Should We Be Concerned about Enhanced Disease after Vaccination?: The Challenges of a Dengue Vaccine

Gavin Screaton and Juthathip Mongkolsapaya
Is There Natural Killer Cell Memory and Can It Be Harnessed by Vaccination?: NK Cell Memory and Immunization Strategies against Infectious

Diseases and Cancer Joseph C. Sun and Lewis L. Lanier

Is There Natural Killer Cell Memory and Can It Be Harnessed by Vaccination?: Natural Killer Cells in Vaccination

Harold R. Neely, Irina B. Mazo, Carmen Gerlach, et al.

Is It Possible to Develop Cancer Vaccines to Neoantigens, What Are the Major Challenges, and How Can These Be Overcome?: Targeting the Right Antigens in the Right Patients Stephen P. Schoenberger

Which Dengue Vaccine Approach Is the Most Promising, and Should We Be Concerned about Enhanced Disease after Vaccination?: There Is Only One True Winner Scott B. Halstead

Which Dengue Vaccine Approach Is the Most Promising, and Should We Be Concerned about Enhanced Disease after Vaccination?: Questions Raised by the Development and Implementation of Dengue Vaccines: Example of the Sanofi

Pasteur Tetravalent Dengue Vaccine Bruno Guy

For additional articles in this collection, see http://cshperspectives.cshlp.org/cgi/collection/

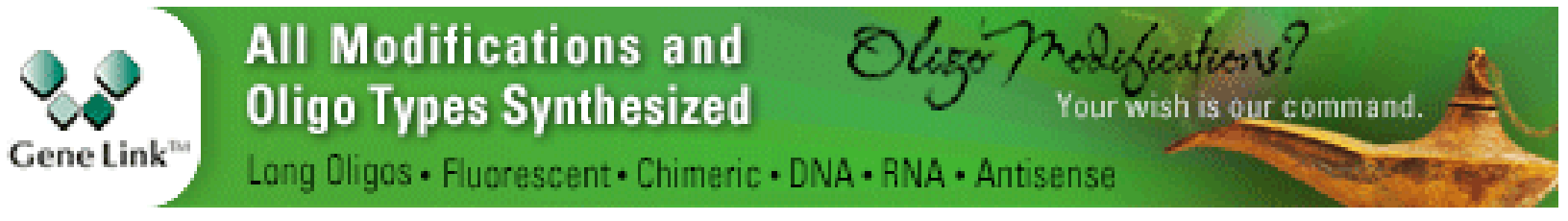


Which Dengue Vaccine Approach Is the Most Promising, and Should We Be Concerned about Enhanced Disease after Vaccination?: The Path to a Dengue Vaccine: Learning from Human Natural Dengue Infection Studies and Vaccine Trials Aravinda M. de Silva and Eva Harris

Is It Possible to Develop a "Universal" Influenza Virus Vaccine?: Potential for a Universal Influenza Vaccine

James E. Crowe, Jr.

Is It Possible to Develop a "Universal" Influenza Virus Vaccine?: Outflanking Antibody Immunodominance on the Road to Universal Influenza Vaccination

Davide Angeletti and Jonathan W. Yewdell
Which Dengue Vaccine Approach Is the Most Promising, and Should We Be Concerned about Enhanced Disease after Vaccination?: The Risks of Incomplete Immunity to Dengue Virus Revealed by Vaccination

Stephen S. Whitehead and Kanta Subbarao

Is It Possible to Develop a "Universal" Influenza Virus Vaccine?: Immunogenetic Considerations Underlying B-Cell Biology in the Development of a Pan-Subtype Influenza A Vaccine Targeting the Hemagglutinin Stem

Sarah F. Andrews, Barney S. Graham, John R. Mascola, et al.

Is It Possible to Develop a "Universal" Influenza Virus Vaccine?: Potential Target Antigens and Critical Aspects for a Universal Influenza Vaccine Florian Krammer, Adolfo García-Sastre and Peter Palese

For additional articles in this collection, see http://cshperspectives.cshlp.org/cgi/collection/

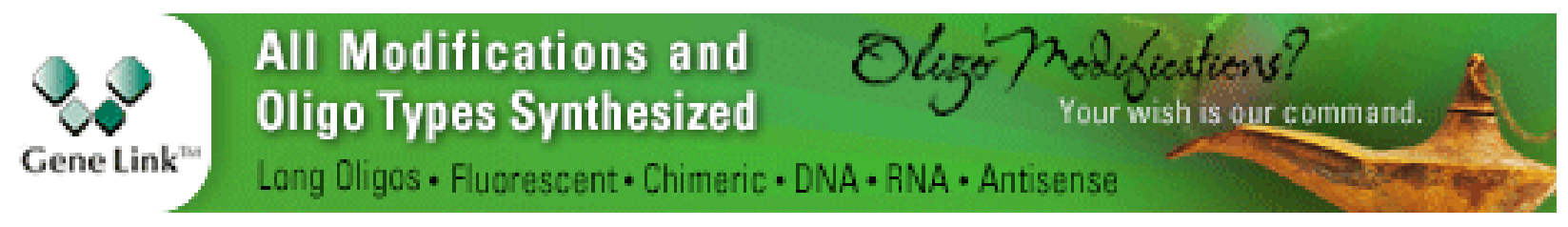

Copyright @ 2018 Cold Spring Harbor Laboratory Press; all rights reserved 